\title{
Field Service Monitoring System for Electric Distributors' Third Party Contractors
}

\author{
Kathreen Charrise E. Garcia and Benilda Eleonor V. Comendador
}

\begin{abstract}
Field service work requires service organizations to have a fast and reliable way of assigning and monitoring field service job orders. The nature of such business often requires employees to be in the field and capabilities such as location mapping and task assignment notification would greatly assist them in performing their work. This paper highlights the importance of mobility and data accessibility in field service work. With the use of the online Field Service Monitoring System and Mobile Application, field service organizations, such as Third Party Contractors of Electric Distributors, can now assign job orders remotely to their employees in the field, providing all the crucial information for performing specific field service task. The online system sends job request notification straight to each Field Service Employee mobile device, allowing a faster way of communicating job responsibilities. The Mobile Application on the other hand provides a portable online access to each job order details. Information such as structure standards, and material list would assist in ensuring the quality of work. Through the use of the Field Service Monitoring System, managers are able to assess which employee fits the job requirement by using customer feedback while field employees can respond to job request faster, are provided with more accurate and up to date information and location mapping together with portable tools in order to show the quality of their work ensuring high quality service.
\end{abstract}

Index Terms-Field service monitoring, Android application, Google cloud messaging, job order assignment.

\section{INTRODUCTION}

The development of various technologies for business clearly shows how the industry recognizes the potential of IT implementation in business organizations. Information systems were developed not only to assist in data processing but also to collect significant data that will be used for upper management decision making. Ubiquitous, mobile and cloud computing, on the other hand, ensures not only the ability of organizations to reach more clients but also to provide consumers with greater power [1]. These technologies not only allow customers to see, compare and select the services they prefer, it also allows them to provide feedback in order for the businesses to know how they can serve their clients better.

One of the organizations greatly assisted by technology is the service sector. The service industry has always been an integral part of the economy. The service industry aims to

Manuscript received December 14, 2015; revised March 13, 2016.

Kathreen Charrise E. Garcia is with Cavite State University, Imus Campus, Cavite, Philippines (e-mail: kceg2001 @ yahoo.com).

Benilda Eleonor V. Comendador is with Polytechnic University of the Philippines, Philippines (e-mail: bennycomendador@yahoo.com). create and provide clients with services rather than products [2]. Service industry includes utilities such as electric distributors, telecommunications, and oil companies as well as professional services such as medicine and software development. Since most of the services provided are a day to day necessity, the service industry became one of the most successful fields of business. For instance, in the Philippines, the service sector has clearly proven its rapid growth. As a developing country, the Philippines has always been known for its agriculture and manufacturing business. Yet the service sector has almost 19.4 million Filipinos under its employment, a number greater than those employed under the manufacturing and agriculture business put together [3].

As defined, the service industry's main commodity is the service it provides to its clients. Because of this, it aims to continuously improve its service quality and efficiency to show better service value. Doing so would lead to better client and service provider trust that will lead to better profitability. With its distinct processes such as job request, job scheduling, employee dispatching and providing services to various locations, such organizations require careful management in order to attain the goal of better service provision.

One of the ways of improving service efficiency and quality is through field service monitoring. Field Service Monitoring is a branch of Field Service Management that provides automation of necessary functionalities for managing the field service of service providing companies. Field Service Monitoring focuses on monitoring job status and assigning service personnel to specific tasks. Such monitoring is very important since the industries' main commodity is its service quality. In addition, since most field service organization operates by assigning jobs, careful work assignment is very crucial in optimizing productivity and service quality. This includes balancing the assigned workload as well as assigning the appropriate job to a specific employee depending on their skills and specializations [4].

In the past, only selected types of service organizations implement techniques in managing field service assignment. Of the three types of service industry, only product delivery and emergency services implement field force automation [5]. Examples of these are automations are those used by logistic services. Another is the automated GPS tracking employed by emergency services in the United States. The third type of service organization, which is after sales service, has only recently found the significance of increasing its focus in managing field assignments through automation.

Because of its features, a field service system has the capability to greatly contribute to a service institutions growth and success [6]. Currently, such systems were able to penetrate a quarter of the service market [7]. Organizations 
such as cable operators and utilities distributor were provided with an easier way to dispatch their employees to different locations. It increases not only a company's capability in customer relation, but also assists in increasing customer satisfaction and most importantly company profitability.

Electric distribution companies handle the provision, monitoring and maintenance of electricity to large scale areas. It involves transmission of electricity from transmission systems used by power plants to individual customer locations. Because of this various systems are utilized in order to properly manage and maintain electric distribution. [8] Since electricity is a necessity, one of the largest service organizations in the Philippines is an electric distributor.

Third Party Contractors accredited by the electric distributors are created in order to further provide quality service to customers. Third Party Contractors handle job request for service structure construction, in this case, service entrance construction. Applications are submitted by customers to the electric distributor branch near them or, directly to a third party contractor. Document processing and service entrance construction is then handled by the third party contractors. Employees of third party contractors are assigned to each job application through text messages and calls. Information regarding the application is provided through the same media if the employee is already in the field. All structure standards are provided by the electric distributors and the third party contractors are required to ensure that all structure follow these quality and safety standards.

Employees of third party contractors are often assigned on the field. Thus, it is of utmost importance for the third party contractors to have a reliable way of communication, in order to assign tasks to its employees in the field.

The development of Field Service Monitoring aimed to assist third party contractors of electric distributors in receiving, managing and dispatching job orders for new meter installations provided by the contractors. The system was designed to receive new meter applications from customers and allow managers to assign job orders to contractors. The system will then notify contractors on their mobile devices and online accounts of the job request. Mobile notification will be done through the use of Google Cloud Messaging. Google Cloud Messaging allows mobile applications to send and receive notifications through the use of the internet [9]. Contractors will then send notification of the job request to its electricians. Electricians would be able to take images of their job progress using their mobile application when the job is completed.

The clients may then provide feedback on how well the electricians, field personnel and contractors handled the job. This will assist the managers and contractors with regard to assigning future job request.

Through this system, contractors are able to assess their field employees through customer feedback, aiding in assigning the employee that performs well in a specific job type. Field employees, with the use of the mobile application, can now receive and respond to job request faster through Push Notification, and are provided with the assistive tools such as actual location mapping and image capture in order to ensure fast, reliable and high quality service provision.

\section{THE DEVELOPED SYSTEM}

Field Service Monitoring System is composed of a website and a mobile application. The website was developed using PHP. The mobile application, on the other hand, is android based and was developed using Java language. Eclipse 4.2 was used as Integrated Development Environment (IDE) for its development. To enable data sharing and accessibility, MYSQL was used as server based database management system. JSON parsing was utilized in order for the mobile application to access the server based data in MYSQL. This ensures that the available information on the website is the same with what is on the mobile device. Google Cloud Messaging was utilized to allow push notification for all new assignments while Google Maps was used for service location mapping. Image capture and upload was provided to show proof of quality of work by the electricians

\section{A. System Architecture}

New job request in the form of new service application is handled by the system through a form on the website where clients provide the required details for service application such as their name, service address and type of location. This is essential since a feasibility study is needed before their application can be approved. A map of the location is available for the client to select the service location for visiting. This detail will then be checked by the electric distributor manager and then assigned to a specific contractor for follow up. If a client already has a preferred contractor, applications will then go straight to the contractors. The contractors will then receive notification on their mobile devices and online accounts of the details of the customer application. The system used Google Cloud Messaging to enable the push notification for the application. Push notifications contain the name of the client assigned to the contractor. Tracking of job orders such as document processing will be posted on the customer's account on the website for them to see their application progress.

Afterwards, contractors can then assign job orders to their field personnel and electricians via mobile or the website. The system can provide suggestions on which electrician is most suitable for the job. New assignment notifications for field employees are provided through the Push Messaging. The field personnel and electricians will receive the details as well as the map of the location for servicing on their mobile devices through the mobile application. The field personnel will visit the location for inspection and to see if the customers follow the structure requirements of the electric distributor. If so, then the field personnel will approve the application and have the customer submit the requirements for document processing. Once the document has been processed, the electrician may now start the construction. An image of the structure standards together with the materials for construction is also available in the mobile application in order to assist the electricians in constructing the service entrance. Electricians can note progress as well as take pictures of the structure after its completion. Customers can provide client feedback to monitor job performance of employees which will then be used by the system to recommend the employee that is most suitable for a specific job type. Fig. 1 shows the system architecture of the Field 
Service Monitoring System.

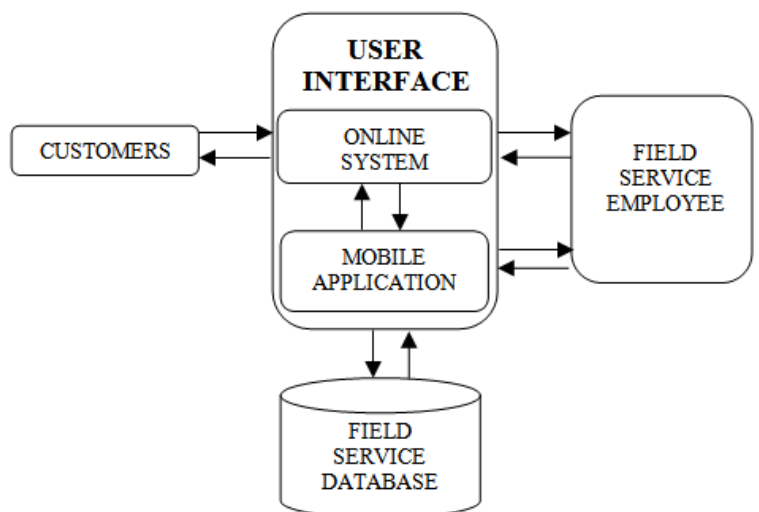

Fig. 1. System architecture of field service monitoring system for electric distributors' third party contractors.

\section{B. Software}

Interfaces were provided in order for the user to interact with the system. The website has a login in screen where the user can log in using their credentials into the system. A dashboard was provided in order for the users to view sales or performance statistics and to navigate around the website. Fig. 2 shows the prototype of the website dashboard.

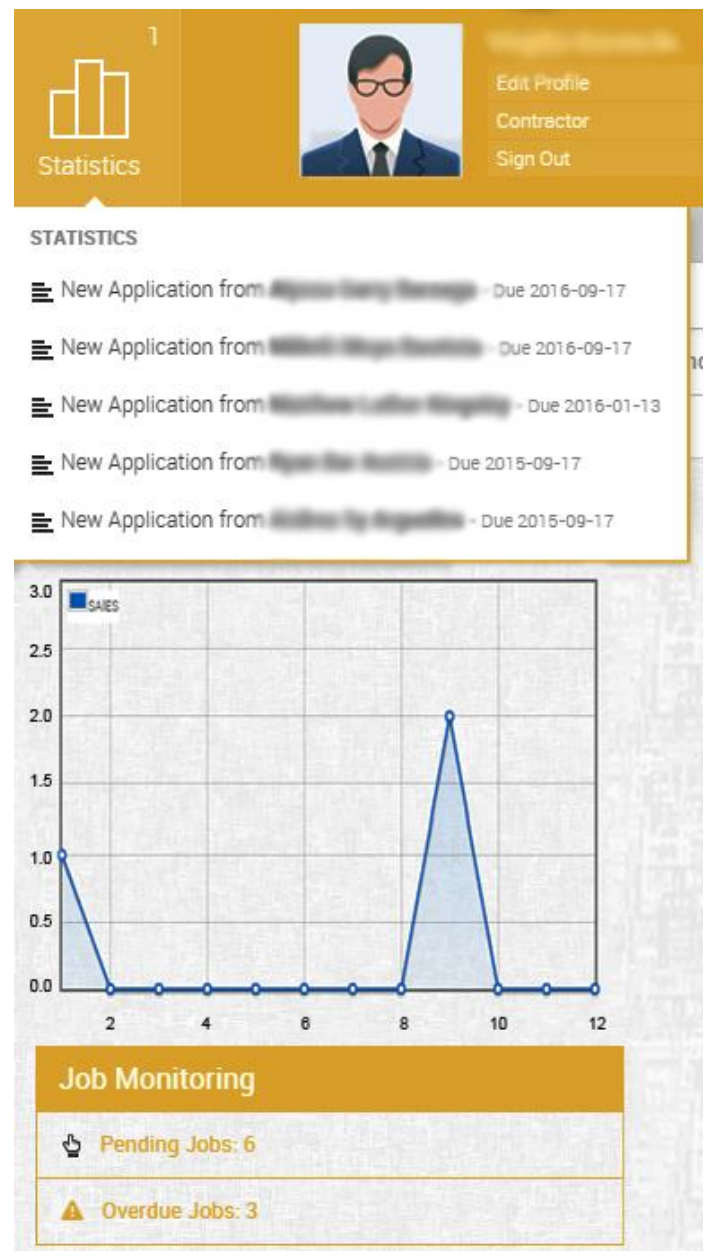

Fig. 2. Dashboard of the field service monitoring system.

The online system has forms for managing srvice applications, job types and employees. It also has a form for customer feedback where employees can be rated by customers.
The mobile application on the other hand allows only field service personnel to access. Fig. 3 shows the prototype of the login screen of the mobile application.

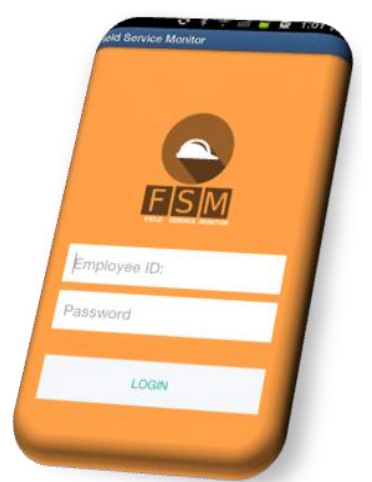

Fig. 3. Login screen of the field service monitoring system - mobile.

The mobile application shows the list of all jobs assigned to the employee. An employee may choose to view all pending job orders or a list of all completed jobs in the past 7 days. Once the employee has selected a client name, the details of the application will be shown by the system. Fig. 4 shows the prototype of the service application details on the mobile application.

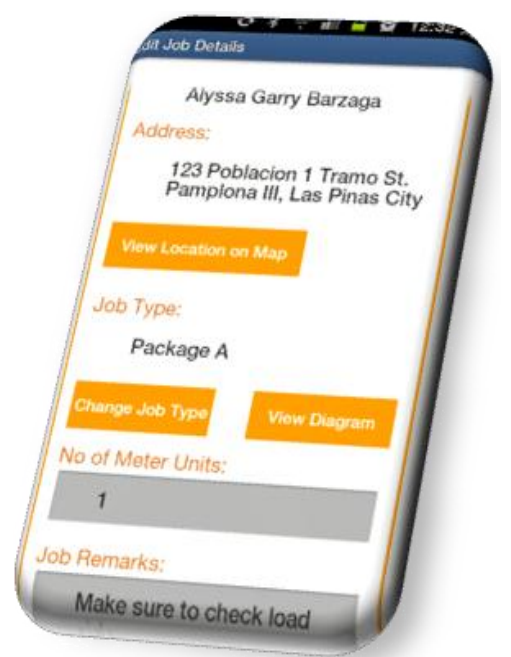

Fig. 4. Service application details.

The application can show the map of the location and also allow electrician to view structure standards of the job. In addition, the application also allows the electricians to take a picture of the location. The image will be uploaded to the server and be viewable using the website.

\section{Research Methods and Techniques}

The research was a descriptive study, focusing on the concerns and problems encountered by Third Party Contractors of Electric Distributors. After gathering all required data, the research utilized the Developmental Method. Developmental method was chosen in order to develop a program for the purpose of improving the existing process or system within an organization. Adaptive Software Development (ASD) was used as software development methodology. Because of its agile nature, ASD allows the developer to develop the system in small increments that will then be checked by the clients. In addition, ASD provides flexibility regarding the software development, allowing 
changes to occur if necessary [10]. A web-based program together with a mobile application for android devices was developed by following the phases in system development. The system aimed to assist the employees in handling their field service task.

Table I shows the number of respondents who participated in the study.

TABLE I: FIELD SERVICE MONITORING SYSTEM RESPONDENTS

\begin{tabular}{ll}
\hline \hline Respondents & No. of Respondents \\
\hline Contractors & 3 \\
Electricians & 14 \\
Field Personnel & 10 \\
Manager & 1 \\
\hline \hline
\end{tabular}

In order to properly evaluate the system, a total of 28 field service employees, specifically, contractors, electricians, field personnel, and electric distributor's branch manager were selected using Non-Probabilistic Purposive Sampling.

The respondents came from selected Third Party Contractors from Las Piñas City.

\section{RESULTS AND DISCUSSION}

The first objective of the research is to find challenges encountered by the employees of Third Party Contractors in performing their field service task. Through a survey, the research found that the most common problem faced by the employees is the use of various medium of communication such as text messages and calls in providing field service information. It was found that the use of such media results to the inaccuracy of information provided to the field service employees, delaying the delivery of service. Another problem often encountered by the employees is finding the actual service location. Since the only provided information regarding the service location is the service address, employees occasionally have a hard time finding the actual service location.

Another objective of the research is to develop a system that will assist Third Party Contractor employees in their field service task and to alleviate, if not remove, the challenges often encountered by such employees in performing their job functions. To test the level of effectiveness, the developed system underwent an evaluation, with the respondents being the selected employees of Third Party Contractors. The level of effectiveness of the system was tested in terms of its Security, Accuracy, Performance and User Friendliness.

Table II shows the summary of findings regarding the respondents' perception on the level of effectiveness in terms of the aforementioned factors.

TABLE II: SUMMARY OF FINDINGS REGARDING THE LEVEL OF EFFECTIVENESS OF THE SYSTEM

\begin{tabular}{ll}
\hline \hline Variables Tested & Mean \\
\hline Security & 4.38 \\
Accuracy & 4.56 \\
Performance & 4.73 \\
User Friendliness & 4.70 \\
\hline \hline
\end{tabular}

After evaluation, the level of effectiveness of the system in terms of Security earned a 4.38 mean, showing that the respondents agreed that the Field Service Monitor was able to ensure the security of gathered data.

With regards to accuracy, the system earned a general mean of 4.56 with the respondents agreeing that the usage of a centralized database to ensure the accuracy of data greatly benefited the business process.

The general mean for the level of effectiveness in terms of performance earned a 4.73 mean. The use of the online system together with the mobile application also assisted the field service employees in both accessing the data remotely and finding the client's service location through the use of maps.

Lastly, the user friendliness of the systems earned a general mean of 4.70. The respondents also agreed that the software was easy to use and user - friendly and that the controls presented in the website and the mobile application performed their assigned function well.

\section{CONCLUSION AND RECOMMENDATION}

Based on the acquired results of the study, the research came up with the following conclusions:

Mobility and accessibility of accurate information were very essential for field service tasks. Due to the manual processing of applications, certain scenarios occur that often results to the delay in the delivery of service, specifically service entrance installation. The medium used in relaying service application information as well as the quality of the information provided and its availability are factors that are of great importance in field service delivery and thus problems that arise regarding the aforementioned factors greatly affect the overall performance of field service work. Such scenarios may not only lessen the quality of service provided by field service organization but also lessen customer satisfaction.

The results of the survey showed the system to be 'VERY EFFECTIVE' in all four factors, namely Security, Accuracy, Performance and User Friendliness.

It is concluded that because of the features available in the mobile application and website of the Field Monitoring System, the problems encountered by field service employees as mentioned earlier may be avoided. The system can assist Third Party Contractors in assigning and monitoring all job orders. In addition, the system also provides suggestions regarding job assignments as it has a feature of ranking electricians depending on the customer ratings. Having both website and the mobile application, the system provides a portable way of accessing and manipulating data as well as managing a certain task or job request. The feature of mapping which is accessible both through the system and the mobile application provided a better guide in order for field service employees to find the location of the area to be serviced. The system will greatly assist employees in their field service tasks.

Over all the system's user friendliness, provision of data security, accuracy and high performance contributed to the overall 'VERY EFFECTIVE' rating as per evaluation of the respondents.

In the future, the researchers may extend the study by adding real time location tracking of the field employees through GPS. Furthermore, automatic queuing of job orders based on priorities and other factors will greatly assist in the 
assigning of task to personnel. Monitoring of all equipment and assets of the organization as well as monitoring of all materials used by electricians in performing job requests would also greatly benefit the organization.

\section{REFERENCES}

[1] J. Maan, "Mobile web - strategy for enterpise success," International Journal on Web Service Computing, pp. 46-53, 2012.

[2] Service Industry, Encyclopadia Britannica Ultimate Reference Suite, Chicago: Encyclopædia Britannica, 2012.

[3] R. M. Mitra, Leveraging Service Sector Growth in the Philippines, Mandaluyong City, Philippines: Asian Development Bank, 2013.

[4] S. S. Shah, A. R. Jaffari, J. Aziz, W. Ejaz, I. Ul-Haq, and S. N. Raza, "Workload and performance of employees," Interdisciplinary Journal of Contemporary Research in Business, pp. 256-261, 2011.

[5] K. Djemai, "The impact of field force automation technology on coordination: The cases of intervention technicians of France telecom," 2012.

[6] S. Dutta and A. J. Pinder, Field Service 2012: The Right Technician, February 2012

[7] W. Mc Neill, M. Maoz, and G. Van Huizen, Magic Quadrant for Field Service Management, October 9, 2013.

[8] N. Maharajan, "GIS based service oritented architecture approach for electric distribution," Journal of Emerging Trends in Computing and Information Sciences, pp. 1567-1581, 2012.

[9] Y. S. Yilmaz, B. I. Aydin, and M. Demirbas, "Google cloud messaging (GCM): An evaluation," in Proc. Global Communications Conference, pp. 2807-2812, 2014

[10] P. Abrahamsson, O. Salo, J. Ronkainen, and J. Warsta, Agile Software Development Methods: Review and Analysis, Helsinki: VTT, 2002.

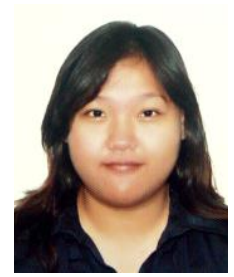

Kathreen Charrise E. Garcia received her undergraduate degree in information technology at Cavite State University, College of Business and Entrepreneurship. She continued her education and earned an MS degree in information technology from Polytechnic University of the Philippines in December 2015. Presently, she is an instructor in Cavite State University, Imus Campus.

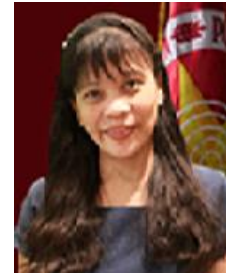

Benilda Eleonor V. Comendador is a member of Science and Engineering Institutes, Philippine Computer Society and Philippine Schools, Universities, and Colleges Computer Education and Systems Society (PSUCCESS). She was a grantee of the Japanese Grant Aid for Human Resource Development Scholarship (JDS) from April 2008 to September 2010. She obtained her master of science degree in Global Information Telecommunication Studies (MSGITS), major in project research at Waseda University, Tokyo Japan in 2010. She was commended for her exemplary performance in completing the said degree from JDS. She finished her master of science degree in information technology at Ateneo Information Technology Institute, Philippines in 2002.

Presently, she is the Chief of the Open University Learning Management System (OU-LMS) and the Program Chair of the Master of Science in Information Technology (MSIT) of the graduate school of the Polytechnic University of the Philippines (PUP). She is an associate professor and was the former chairperson of the Department of Information Technology of the College of Computer Management and Information Technology of PUP.

She attended various local and international computer related trainings and seminars. She was the country's representative to the Project Management Course in 2005, which was sponsored by the Center for International Computerization Cooperation (CICC) in Tokyo, Japan together with other 9 representatives from various ASEAN countries.

She presented several research papers in various international conferences including: 1) 2009 IEICE Society Conference, Niigata Japan; 2) e-Case \& e-Tech in 2010 and in 2012 by International Conference on e-Commerce, e-Administration, e-Society, e-Education, and e-Technology, Macau; 3) International Journal of Arts \& Sciences (IJAS) Conference for Academic Disciplines in Las Vegas and 4) The Fifth International Conference on Mobile Computing and Ubiquitous Networking Seattle, U.S.A. 

Computer Science and Image Processing 
